\section{(- OPEN ACCESS}

\title{
Efficacy and safety of tocilizumab in patients with refractory Takayasu arteritis: results from a randomised, double-blind, placebo-controlled, phase 3 trial in Japan (the TAKT study)
}

\author{
Yoshikazu Nakaoka, ${ }^{1}$ Mitsuaki Isobe, ${ }_{1}^{2}$ Syuji Takei, ${ }^{3}$ Yoshiya Tanaka, ${ }_{1}^{4}$ Tomonori Ishii,
} Shumpei Yokota, ${ }^{6}$ Akira Nomura, ${ }^{7}$ Seitaro Yoshida, ${ }^{7}$ Norihiro Nishimoto ${ }^{8}$

\section{Handling editor Tore K Kvien \\ - Additional material is published online only. To view please visit the journal online (http://dx.doi.org/10.1136/ annrheumdis-2017-211878).}

${ }^{1}$ Department of Vascular Physiology, National Cerebral and Cardiovascular Center Research Institute, Osaka, Japan ${ }^{2}$ Department of Cardiovascular Medicine, Tokyo Medical and Dental University, Tokyo, Japan ${ }^{3}$ Faculty of Medicine, School of Health Sciences, Kagoshima University, Kagoshima, Japan ${ }^{4}$ First Department of Internal Medicine, School of Medicine, University of Occupational and Environmental Health Kitakyushu, Japan

${ }^{5}$ Clinical Research, Innovation and Education Center, Tohoku University Hospital, Sendai, Japan

${ }^{6}$ Laboratory of Pediatric Research, Institute of Tokyo Medical School, Tokyo, Japan ${ }^{7}$ Chugai Pharmaceutical Co., Ltd., Tokyo, Japan

${ }^{8}$ Department of Molecular Regulation for Intractable Disease, Institute of Medical Science, Tokyo Medical University, Tokyo, Japan

\section{Correspondence to} Dr Yoshikazu Nakaoka, Department of Vascular Physiology, National Cerebral and Cardiovascular Center Research Institute, Osaka 5658565, Japan; ynakaoka@ncvc.go.jp

Received 1 June 2017 Revised 25 October 2017 Accepted 31 October 2017 Published Online First 30 November 2017

\section{Check for updates}

To cite: Nakaoka Y, Isobe $\mathrm{M}_{\text {, }}$ Takei S, et al. Ann Rheum Dis 2018;77:348-354.

\section{ABSTRACT}

Objective To investigate the efficacy and safety of the interleukin-6 receptor antibody tocilizumab in patients with Takayasu arteritis (TAK).

Methods Patients with TAK who had relapsed within the previous 12 weeks were induced into remission with oral glucocorticoid therapy. In this double-blind, placebo-controlled trial, patients were randomly assigned 1:1 to receive weekly tocilizumab $162 \mathrm{mg}$ or placebo subcutaneously, and oral glucocorticoids were tapered $10 \% /$ week from week 4 to a minimum of $0.1 \mathrm{mg} / \mathrm{kg} /$ day until 19 patients relapsed. The primary endpoint was time to relapse of TAK, defined as $\geq 2$ of the following: objective systemic symptoms, subjective systemic symptoms, elevated inflammation markers, vascular signs and symptoms or ischaemic symptoms.

Results The intent-to-treat and safety populations included 18 tocilizumab-treated and 18 placebotreated patients. The per-protocol set (PPS) included 16 tocilizumab-treated and 17 placebo-treated patients. HRs for time to relapse of TAK were $0.41(95.41 \% \mathrm{CI} 0.15$ to $1.10 ; p=0.0596)$ in the intent-to-treat population (primary endpoint) based on relapse in eight tocilizumabtreated and 11 placebo-treated patients and 0.34 $(95.41 \% \mathrm{Cl} 0.11$ to $1.00 ; p=0.0345)$ in the PPS. The secondary endpoints, time to relapse assessed by Kerr's definition and clinical symptoms only, were consistent with the primary endpoint. Serious adverse events were reported in one tocilizumab-treated and two placebotreated patients. There were no serious infections and no deaths.

Conclusion Although the primary endpoint was not met, the results suggest favour for tocilizumab over placebo for time to relapse of TAK without new safety concerns. Further investigation is warranted to confirm the efficacy of tocilizumab in patients with refractory TAK.

Trial registration number JapicCTI-142616.

\section{INTRODUCTION}

Takayasu arteritis (TAK) is characterised by aortitis affecting the aorta and its major branches, coronary arteries and pulmonary arteries. ${ }^{1}$ TAK is a rare inflammatory disease of unknown aetiology, with an estimated incidence of 2.6 cases per million in the USA. ${ }^{23}$ Prevalence may be higher in Japan, with approximately 60 cases per million. ${ }^{4}$ TAK occurs more frequently in females, usually from approximately 20 years of age. ${ }^{1}$ Disease manifestations include systemic symptoms, head and neck symptoms (dizziness, headache, syncope, jaw claudication, neck pain), upper limb problems, hypertension and body pain. ${ }^{4}$ Presenting symptoms vary greatly depending on vascular involvement and the degree of disease progression. ${ }^{4}$ Longterm inflammation in patients with TAK can cause severe vascular injury-including thickening of the aorta and its main branches, fibrosis, stenosis and thrombus formation-potentially leading to organ failure. ${ }^{56}$ Inflammatory cells, particularly T-helper 17 (Th17) and Th1 cells, and cytokines, including interferon- $\gamma$, tumour necrosis factor- $\alpha$ (TNF- $\alpha$ ), interleukin-6 (IL-6), IL-8, IL-17A and IL-18, are increased in patients with TAK. ${ }^{7-11}$ Furthermore, elevated IL-6 levels are associated with increased disease activity. ${ }^{78}$

Glucocorticoids (GCs), the first-line therapy for the treatment of TAK, are often associated with adverse effects when used long term, and patients frequently relapse during GC tapering. ${ }^{12}$ Other immunosuppressive agents, including methotrexate, azathioprine and mycophenolate mofetil, may be used if relapse occurs while the patient is receiving $\mathrm{GC}^{13-15}$; however, these agents have not demonstrated consistent clinical benefits or steroidsparing effects. ${ }^{12} 16$ Although treatment with TNF inhibitors has shown clinical responses and a steroid-sparing effect in retrospective or observational studies in patients with TAK refractory to conventional immunosuppressive therapy, ${ }^{12}{ }^{17-20}$ no randomised controlled study has been reported to date.

Tocilizumab, a recombinant, humanised, antiIL-6 receptor (IL-6R) monoclonal antibody, was first reported by Nishimoto et $a l^{21}$ for the successful treatment of a patient with TAK. Since then, clinical responses and a steroid-sparing effect have been demonstrated in patients with refractory TAK in case reports and observational studies, ${ }^{16}{ }^{21-26}$ including patients refractory to TNF inhibitors. ${ }^{23} 2426$ Overall, clinical and laboratory responses have been reported in more than $80 \%$ of patients treated with tocilizumab. ${ }^{12} 25$ The efficacy and safety of tocilizumab investigated in the first randomised, placebo-controlled, doubleblind, parallel-group, comparative study in patients with TAK, the TAKT study (Japan Pharmaceutical 
Table 1 Baseline demographics and disease characteristics (ITT population)

\begin{tabular}{|c|c|c|}
\hline & $\begin{array}{l}\text { Tocilizumab } \\
\text { subcutaneous } \\
162 \mathrm{mg} / \text { week } \\
(\mathrm{n}=18)\end{array}$ & $\begin{array}{l}\text { Placebo } \\
(n=18)\end{array}$ \\
\hline Female, n (\%) & $16(88.9)$ & $15(83.3)$ \\
\hline $\begin{array}{l}\text { Age at informed consent, years, } \\
\text { mean } \pm S D \text { (median) }\end{array}$ & $31.1 \pm 18.1(26.5)$ & $30.8 \pm 13.1(27.0)$ \\
\hline \multicolumn{3}{|l|}{ Age category, $\mathrm{n}(\%)$} \\
\hline$<18$ years & $4(22.2)$ & $2(11.1)$ \\
\hline $18-<65$ years & $12(66.7)$ & $15(83.3)$ \\
\hline$\geq 65$ years & $2(11.1)$ & $1(5.6)$ \\
\hline $\begin{array}{l}\mathrm{GC} \text { dose* at baseline, } \mathrm{mg} / \mathrm{kg}, \text { mean } \pm \mathrm{SD} \\
\text { (median) }\end{array}$ & $0.57 \pm 0.19(0.50)$ & $0.52 \pm 0.16(0.45)$ \\
\hline \multicolumn{3}{|l|}{ GC dose* category, n (\%) } \\
\hline$<0.6 \mathrm{mg} / \mathrm{kg}$ & $13(72.2)$ & $14(77.8)$ \\
\hline $0.6-<0.8 \mathrm{mg} / \mathrm{kg}$ & $2(11.1)$ & $2(11.1)$ \\
\hline$\geq 0.8 \mathrm{mg} / \mathrm{kg}$ & $3(16.7)$ & $2(11.1)$ \\
\hline $\begin{array}{l}\text { Disease duration, years, mean } \pm \text { SD } \\
\text { (median) }\end{array}$ & $6.46 \pm 7.37(3.33)$ & $3.57 \pm 4.03(2.89)$ \\
\hline \multicolumn{3}{|l|}{ Classification of Takayasu arteritis, $\mathrm{n}(\%)$} \\
\hline I & $2(11.1)$ & $2(11.1)$ \\
\hline IIA & $2(11.1)$ & $3(16.7)$ \\
\hline IIB & $3(16.7)$ & $5(27.8)$ \\
\hline III & $3(16.7)$ & $1(5.6)$ \\
\hline IV & 0 & 0 \\
\hline V & $8(44.4)$ & $7(38.9)$ \\
\hline HLA-B52 positive, n (\%) & $7(38.9)$ & $13(72.2)$ \\
\hline
\end{tabular}

*Prednisolone equivalent (minimum dose was $0.4 \mathrm{mg} / \mathrm{kg} / \mathrm{day}$ because patients who experienced relapse despite $\mathrm{GC}$ administration of at least $0.2 \mathrm{mg} / \mathrm{kg} /$ day were enrolled and received at least twice the dose they were receiving when relapse occurred).

GC, glucocorticoid; ITT, intent-to-treat.

Information Center number, JapicCTI-142616), are now reported.

\section{METHODS}

\section{Patients}

Patients 12 years of age or older at the time of informed consent (obtained from 24 September 2014) with diagnoses of TAK based on the Japanese Guidelines for Management of Vasculitis Syndrome $2008^{1}$ were enrolled (2 October 2014-31 August 2015). Patients had to have a relapse of TAK (see online supplementary table 1 for definitions of relapse) within 12 weeks before enrolment despite having received treatment with oral GC at a prednisolone-equivalent dose of at least $0.2 \mathrm{mg} / \mathrm{kg} / \mathrm{day}$ (see online supplementary appendix for exclusion criteria).

All patients gave written informed consent to participate in the study according to national requirements (signed by the patient if $\geq 20$ years of age or by the patient and a legally acceptable representative if $<20$ years of age). The study was conducted in accordance with the Declaration of Helsinki and Good Clinical Practice and was approved by the institutional review boards of the medical institutions.

\section{Study design, randomisation and masking}

This double-blind, placebo-controlled, multicentre trial was designed to evaluate the steroid-sparing effect of tocilizumab. To induce remission, patients who experienced TAK relapse received GCs at a dose at least twice that of the dose at relapse.
The first dose of study treatment in the double-blind period was administered after remission from TAK for $\geq 1$ week. Patients were randomly assigned $(1: 1)$ using a permuted block method to receive weekly injections of tocilizumab $162 \mathrm{mg}$ or placebo subcutaneously; background oral GC dose was tapered by $10 \%$ per week from week 4 to a minimum of $0.1 \mathrm{mg} / \mathrm{kg} / \mathrm{day}$ according to the following formula: GC dose at week $n=0.9^{(\mathrm{N}-3)}(\mathrm{GC}$ dose at baseline) when $n \geq 4$. Randomisation was stratified by prednisolone-equivalent oral GC dose $(<0.6 \mathrm{mg} / \mathrm{kg} / \mathrm{day}, \geq 0.6-<0.8 \mathrm{mg}$ / $\mathrm{kg} /$ day or $\geq 0.8 \mathrm{mg} / \mathrm{kg} /$ day). Patients, investigators and study personnel were masked to randomised treatment assignment. The double-blind period ended, in accordance with the study protocol, when relapse of TAK occurred in 19 patients. Patients who completed the double-blind period were followed during open-label extended treatment with tocilizumab.

\section{Assessments}

The primary endpoint was time to relapse of TAK according to protocol-defined criteria (see online supplementary table 1). Relapse of TAK was defined as assessment of 'signs of relapse present' as judged by the investigator for at least two of five categories: objective systemic symptoms; subjective systemic symptoms; elevated inflammation markers; vascular signs and symptoms; ischaemic symptoms. TAK had to be confirmed as the cause of relapse in each patient by eliminating other causes such as infections, allergic disorders and unexplained physical symptoms. For the primary evaluation, causes of relapse other than TAK were eliminated based on $\geq 2$ consecutive assessments for objective and subjective systemic symptoms, elevated inflammation markers and vascular signs and symptoms unless urgent treatment was required, in which case a single assessment sufficed. Even if signs of relapse were not present in two of five categories, relapse was considered to have occurred if severe aortic valve incompetence accompanied by symptoms of cardiac failure occurred under 'vascular signs and symptoms' or if Common Terminology Criteria for Adverse Events (CTCAE) grade 2 or higher (grade $\geq 3$ for myocardial infarction) occurred under 'ischaemic symptoms'. Patients, investigators, and study personnel were blinded to $C$ reactive protein (CRP) results during the double-blind period. If CRP values were required to determine relapse, the clinical laboratory confirmed whether they met the definition of relapse. Remission was defined as the absence of any of the five signs and symptoms described for relapse.

Secondary endpoints included time to relapse of TAK according to Kerr's definition ${ }^{3}$ or based on clinical symptoms only. Occurrence of each of the five categories for symptoms of relapse and imaging evaluation were also investigated as secondary endpoints. Imaging was performed using contrast-enhanced CT or MRI if CT was not feasible, before the first dose of study drug and before each dose every 24 weeks thereafter (optional if imaging had been performed in the previous 8 weeks). Imaging was also performed within 7 days of signs of relapse and at the last observation in the double-blind period or at study withdrawal (optional if imaging had been performed in the previous 12 weeks). Changes from baseline in imaging results were evaluated qualitatively by a radiologist or a physician at each site (see online supplementary appendix for the imaging protocol).

Safety was assessed as the incidence and severity of adverse events (AEs), adverse drug reactions and laboratory values according to CTCAE version 4.0. Blood samples for anti-tocilizumab antibody screening were collected every 4 weeks for 
A

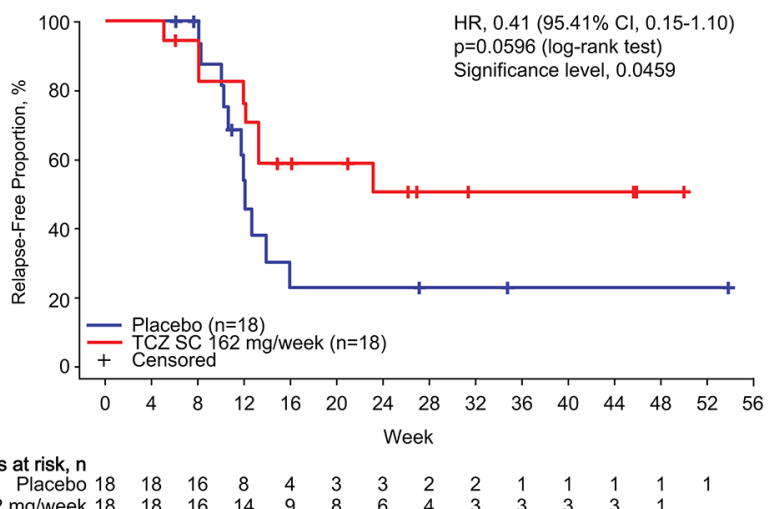

$\begin{array}{rllllllllllll}\text { Placebo } 18 & 18 & 16 & 8 & 4 & 3 & 3 & 2 & 2 & 1 & 1 & 1 & 1 \\ \text { mg/week } 18 & 18 & 16 & 14 & 9 & 8 & 6 & 4 & 3 & 3 & 3 & 3 & 1\end{array}$
B

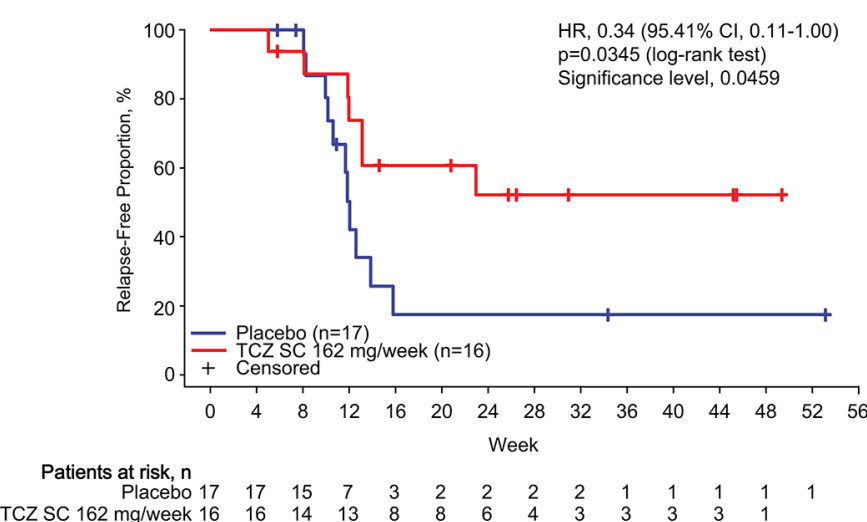

Figure 1 Kaplan-Meier curves showing time to relapse* in the intent-to-treat population (primary endpoint, A) and per-protocol set (sensitivity analysis, B) according to the protocol definition. *Two or more of five signs of relapse present: objective systemic symptoms, subjective systemic symptoms, elevated inflammation markers, vascular signs and symptoms, ischaemic symptoms. SC, subcutaneous; TCZ, tocilizumab.

the first 12 weeks and every 12 weeks thereafter. The screening assay was performed as previously described. ${ }^{27}$

\section{Statistical analyses}

The primary efficacy analysis was conducted in the intent-to-treat (ITT) population, and safety was assessed in the safety population. Additional analysis was conducted in the per-protocol set (PPS) to evaluate sensitivity of the primary analysis. The primary endpoint, time to relapse of TAK, was estimated using KaplanMeier analysis, and the superiority of tocilizumab subcutaneous $162 \mathrm{mg} /$ week compared with placebo was evaluated based on a two-sided $\mathrm{p}$ value lower than the significance level at the final analysis $(\alpha=0.0459$; O'Brien-Fleming-type alpha spending function) determined according to preplanned interim analysis and tested based on a log-rank test stratified by age category $(<18$ years, $18-<65$ years, $\geq 65$ years). HRs and corresponding CIs

Table 2 Time to relapse of Takayasu arteritis according to various definitions

\begin{tabular}{|c|c|c|}
\hline ITT population & Tocilizumab subcutaneous $162 \mathrm{mg} /$ week $(\mathrm{n}=18$ ) & Placebo $(n=18)$ \\
\hline \multicolumn{3}{|l|}{ Protocol definition* } \\
\hline Patients who relapsed, $\mathrm{n}(\%)$ & $8(44.4)$ & $11(61.1)$ \\
\hline Treatment duration, weeks, median & 19.00 & 12.86 \\
\hline Time to relapse, $\uparrow$ weeks, median $(95 \% \mathrm{Cl})$ & NE (12.1 to NE) & $12.1(10.7$ to 16.0$)$ \\
\hline HR $(95.41 \% \mathrm{Cl}) ; \mathrm{p}$ value $\ddagger$ & \multicolumn{2}{|c|}{$0.41(0.15$ to 1.10$) ; p=0.0596$} \\
\hline Estimated relapse-free rate at week $24, \%(95 \% \mathrm{Cl}) \dagger$ & $50.6(25.4$ to 75.8$)$ & $22.9(0.4$ to 45.4$)$ \\
\hline \multicolumn{3}{|l|}{ Kerr's definition§ } \\
\hline Patients who relapsed, $\mathrm{n}(\%)$ & $8(44.4)$ & $11(61.1)$ \\
\hline Time to relapse, $†$ weeks, median $(95 \% \mathrm{Cl})$ & NE (12.1 to NE) & $12.1(10.7$ to 16.0$)$ \\
\hline HR $(95.41 \% \mathrm{Cl})$; $p$ value & \multicolumn{2}{|c|}{$0.41(0.15$ to 1.10$) ; p=0.0596$} \\
\hline Estimated relapse-free rate at week $24, \%(95 \% \mathrm{Cl}) \dagger$ & $50.6(25.4$ to 75.8$)$ & $22.9(0.4$ to 45.4$)$ \\
\hline \multicolumn{3}{|l|}{ Clinical definitionף } \\
\hline Patients who relapsed, $\mathrm{n}(\%)$ & $11(61.1)$ & $11(61.1)$ \\
\hline Time to relapse, $†$ weeks, median $(95 \% \mathrm{Cl})$ & 16.0 (8.1 to $\mathrm{NE})$ & $12.0(8.3$ to 16.0$)$ \\
\hline HR $(95.41 \% \mathrm{Cl}) ; p$ value $\ddagger$ & \multicolumn{2}{|c|}{$0.70(0.29$ to 1.70$) ; p=0.4224$} \\
\hline Estimated relapse-free rate at week $24, \%(95 \% \mathrm{Cl})$ & 30.0 (5.3 to 54.7$)$ & $24.6(1.2$ to 48.1$)$ \\
\hline Per-protocol population & Tocilizumab subcutaneous $162 \mathrm{mg} /$ week $(n=16)$ & Placebo $(n=17)$ \\
\hline \multicolumn{3}{|l|}{ Protocol definition* } \\
\hline Patients who relapsed, $\mathrm{n}(\%)$ & $7(43.8)$ & $11(64.7)$ \\
\hline Treatment duration, weeks, median & 21.00 & 12.86 \\
\hline Time to relapse, $†$ weeks, median $(95 \% \mathrm{Cl})$ & NE (13.3 to NE) & $12.1(10.7$ to 14.0$)$ \\
\hline HR $(95.41 \% \mathrm{Cl}) ; \mathrm{p}$ valueł & \multicolumn{2}{|c|}{$0.34(0.11$ to 1.00$) ; p=0.0345$} \\
\hline Estimated relapse-free rate at week $24, \%(95 \% \mathrm{Cl}) \dagger$ & $51.7(25.3$ to 78.0$)$ & $16.7(0.0$ to 37.5$)$ \\
\hline
\end{tabular}

*Two or more of five signs of relapse present: objective systemic symptoms, subjective systemic symptoms, elevated inflammation markers, vascular signs and symptoms, ischaemic symptoms.

tKaplan-Meier estimate.

$\ddagger$ Stratified by age $(<18,18-<65, \geq 65$ years).

$\S$ Two or more of four signs of relapse present: systemic symptoms (objective or subjective), elevated inflammation markers, vascular signs and symptoms and ischaemic symptoms, imaging (enhanced CT or MRI).

१One or more of four signs of relapse present: objective systemic symptoms, subjective systemic symptoms, vascular signs and symptoms, ischaemic symptoms. ITT, intent-to-treat; NE, not evaluable. 
Table 3 Symptoms of Takayasu arteritis at relapse (ITT population)

\begin{tabular}{lll}
\hline & $\begin{array}{l}\text { Tocilizumab } \\
\text { subcutaneous } \\
162 \mathrm{mg} / \text { week } \\
(\mathrm{n}=18)\end{array}$ & $\begin{array}{l}\text { Placebo } \\
(\mathrm{n}=18)\end{array}$ \\
\hline Patients who relapsed, $\mathrm{n}$ & 8 & 11 \\
\hline Patients with symptoms, $\mathrm{n}(\%)^{*}$ & & \\
\hline \multicolumn{1}{|c|}{ Systemic symptoms (objective assessment) } & $1(12.5)$ & $4(36.4)$ \\
\hline Systemic symptoms (subjective assessment) & $8(100)$ & $9(81.8)$ \\
\hline Elevated inflammation marker & $2(25.0)$ & $5(45.5)$ \\
\hline Vascular signs and symptoms & $7(87.5)$ & $9(81.8)$ \\
\hline Ischaemic symptoms & $2(25.0)$ & $2(18.2)$ \\
\hline Image evaluation, $\mathrm{n}(\%)$ & $2(25.0)$ & $1(9.1)$ \\
\hline
\end{tabular}

*Percentages are based on the number of patients who relapsed.

ITT, intent-to-treat.

for tocilizumab subcutaneous $162 \mathrm{mg}$ compared with placebo were estimated using Cox regression analysis stratified by age category. Based on a review before unblinding, analysis stratified by age category was applied instead of the non-stratified analysis planned at study initiation (see online supplementary appendix). The non-stratified analysis was also conducted as a sensitivity analysis. The statistical software used was SAS V.9.2 (SAS Institute).

\section{RESULTS}

\section{Patients}

Thirty-six patients were enrolled in the study; 18 received tocilizumab subcutaneously $162 \mathrm{mg} /$ week and 18 received placebo. The ITT and safety populations included all 36 patients. The PPS included 16 tocilizumab-treated patients and 17 placebo-treated patients; one patient who decreased the GC dose earlier than prescribed due to safety reasons and one who increased the GC dose due to prescription error were excluded from the tocilizumab group, and one patient for whom GC dosing was interrupted due to a serious adverse event (SAE) was excluded from the placebo group. No patients withdrew from the study during the double-blind period. Baseline demographics and disease characteristics were generally well balanced between the treatment groups. Mean \pm SD age of patients at informed consent was $31.1 \pm 18.1$ in the tocilizumab group and $30.8 \pm 13.1$ in the placebo group, and mean \pm SD dose of GC at baseline was $0.57 \pm 0.19$ and $0.52 \pm 0.16 \mathrm{mg} / \mathrm{kg} / \mathrm{day}$, respectively. Thirty-nine percent of patients in the tocilizumab group and $72 \%$ in the placebo group were HLA-B52 positive (table 1).

\section{Efficacy}

The HR for time to relapse of TAK according to protocol-defined criteria (primary endpoint) in the ITT population was 0.41 (95.41\% CI 0.15 to $1.10 ; \mathrm{p}=0.0596$ ) (figure $1 \mathrm{~A}$, table 2 ), indicating that there was no significant difference between tocilizumab and placebo. Relapse occurred in eight tocilizumab-treated patients (44.4\%) and 11 placebo-treated patients (61.1\%). The median treatment durations were 19.00 weeks in the tocilizumab group and 12.86 weeks in the placebo group. Estimated relapse-free rates at week 24 were 50.6\% $(95 \% \mathrm{CI}$ $25.4 \%$ to $75.8 \%$ ) and $22.9 \%$ (95\% CI $0.4 \%$ to $45.4 \%)$, respectively. Symptoms of the five categories observed at relapse are shown in table 3. Major symptoms of relapse were subjective systemic symptoms reported in $100 \%$ and $81.8 \%$ of tocilizumab-treated and placebo-treated patients and vascular signs and symptoms reported in $87.5 \%$ and $81.8 \%$, respectively.

In the PPS sensitivity analysis, the HR was $0.34(95.41 \%$ CI 0.11 to $1.00 ; p=0.0345)$, indicating longer time to relapse in the tocilizumab group than the placebo group (figure $1 \mathrm{~B}$, table 2 ). Relapse occurred in seven tocilizumab-treated patients $(43.8 \%)$ and 11 placebo-treated patients $(64.7 \%)$ in the PPS. Estimated relapse-free rates at week 24 in the PPS were $51.7 \%(95 \% \mathrm{CI}$ $25.3 \%$ to $78.0 \%$ ) in the tocilizumab group and $16.7 \%$ (95\% CI $0.0 \%$ to $37.5 \%$ ) in the placebo group. The non-stratified analysis in the ITT population resulted in a HR of $0.48(95.41 \% \mathrm{CI}$ 0.19 to $1.23 ; \mathrm{p}=0.1060)$.

Results for the secondary endpoint, time to relapse of TAK according to Kerr's definition, were the same as those for the primary endpoint ( $\mathrm{HR}, 0.41 ; 95.41 \% \mathrm{CI} 0.15$ to 1.10 ; $\mathrm{p}=0.0596$ ) (table 2). There was no significant difference between tocilizumab and placebo in time to relapse according to clinical symptoms only (HR, $0.70 ; 95.41 \%$ CI 0.29 to 1.70 ; $\mathrm{p}=0.4224)$ (table 2).

\begin{tabular}{|c|c|c|c|c|c|c|c|c|c|c|c|}
\hline \multirow[b]{2}{*}{ Symptoms } & \multirow[b]{2}{*}{$\begin{array}{r}\text { Total } \\
\mathrm{n} \\
\end{array}$} & \multicolumn{3}{|c|}{$\begin{array}{c}\text { TCZ SC } \\
162 \mathrm{mg} / \text { week } \\
(\mathrm{n}=18)\end{array}$} & \multicolumn{3}{|c|}{$\begin{array}{l}\text { Placebo } \\
(n=18)\end{array}$} & \multirow[b]{2}{*}{$\mathrm{HR}$} & \multirow{2}{*}{$\begin{array}{c}95 \% \\
\text { Wald } \mathrm{Cl} \\
\end{array}$} & \multirow{2}{*}{$\begin{array}{r}\text { TCZ SC } \\
162 \mathrm{mg} / \text { week } \\
\text { better }\end{array}$} & \multirow[b]{2}{*}{$\begin{array}{l}\text { Placebo } \\
\text { better }\end{array}$} \\
\hline & & $\mathbf{n}$ & Events & $\begin{array}{c}\text { Median } \\
\text { (days) }\end{array}$ & $\mathbf{n}$ & Events & $\begin{array}{c}\text { Median } \\
\text { (days) }\end{array}$ & & & & \\
\hline $\begin{array}{l}\text { Systemic Symptoms } \\
\text { (Objective Assessment) }\end{array}$ & 36 & 18 & 2 & NE & 18 & 5 & NE & 0.27 & $(0.05-1.45)$ & & + \\
\hline $\begin{array}{l}\text { Systemic Symptoms } \\
\text { (Subjective Assessment) }\end{array}$ & 36 & 18 & 7 & NE & 18 & 9 & 89.0 & 0.51 & $(0.18-1.45)$ & & + \\
\hline Elevated Inflammation Marker & 36 & 18 & 1 & NE & 18 & 4 & NE & 0.17 & $(0.02-1.55)$ & & $H$ \\
\hline $\begin{array}{l}\text { Vascular Signs and } \\
\text { Symptoms }\end{array}$ & 36 & 18 & 9 & 162.0 & 18 & 10 & 85.0 & 0.54 & $(0.21-1.39)$ & & -1 \\
\hline Ischemic Symptoms & 36 & 18 & 2 & NE & 18 & 2 & NE & 0.97 & $(0.13-6.98)$ & & \\
\hline Image Evaluation & 35 & 18 & 4 & NE & 17 & 3 & NE & 0.69 & $(0.13-3.55)$ & $\longmapsto$ & $\longrightarrow$ \\
\hline
\end{tabular}

Figure 2 Forest plot showing the HR for each symptom in the protocol-based definition of relapse (intent-to-treat population). Data are based on Cox regression analysis and stratified by age $(<18,18-<65, \geq 65$ years). HRs and $95 \%$ Cls are shown in the plot. NE, not evaluable; SC, subcutaneous; TCZ, tocilizumab. 
Table 4 Safety summary

\begin{tabular}{|c|c|c|}
\hline & $\begin{array}{l}\text { Tocilizumab } \\
\text { subcutaneous } \\
162 \mathrm{mg} / \text { week } \\
(\mathrm{n}=18)\end{array}$ & $\begin{array}{l}\text { Placebo } \\
(n=18)\end{array}$ \\
\hline Patients with $\geq 1 \mathrm{AE}$ & $14(77.8)$ & $11(61.1)$ \\
\hline Events, $\mathrm{n}$ & 38 & 31 \\
\hline Patients with $\geq 1$ adverse drug reaction & $5(27.8)$ & $3(16.7)$ \\
\hline \multicolumn{3}{|l|}{ Most frequent AEs by SOC* } \\
\hline Infections and infestations & $9(50.0)$ & $6(33.3)$ \\
\hline Gastrointestinal disorders & $3(16.7)$ & $5(27.8)$ \\
\hline Skin and subcutaneous tissue disorders & $6(33.3)$ & $1(5.6)$ \\
\hline Eye disorders & $1(5.6)$ & $2(11.1)$ \\
\hline Nervous system disorders & $2(11.1)$ & $1(5.6)$ \\
\hline Respiratory, thoracic and mediastinal disorders & 0 & $3(16.7)$ \\
\hline Investigations & 0 & $2(11.1)$ \\
\hline Psychiatric disorders & $1(5.6)$ & $1(5.6)$ \\
\hline Patients with $\geq 1 \mathrm{SAE}$ & $1(5.6)$ & $2(11.1)$ \\
\hline Events, $\mathrm{n}$ & 1 & 3 \\
\hline \multicolumn{3}{|l|}{ SAEs by SOC } \\
\hline Eye disorders & $1(5.6)$ & $1(5.6)$ \\
\hline Gastrointestinal disorders & 0 & $1(5.6)$ \\
\hline Vascular disorders & 0 & $1(5.6)$ \\
\hline \multicolumn{3}{|c|}{$\begin{array}{l}\text { Data are } \mathrm{n}(\%) \text {. } \\
\text { No injection site reactions, systemic injection reactions or deaths occurred during } \\
\text { the study. }\end{array}$} \\
\hline
\end{tabular}

Cox regression analysis stratified by age category suggested that there may be a favourable effect for tocilizumab in each of the five signs or symptoms of relapse included in the protocol definition used for the primary endpoint and in imaging evaluations (figure 2).

Eight tocilizumab-treated and three placebo-treated patients decreased their GC dose to the minimum dose. Because the double-blind period of the study ended when 19 events of relapse had occurred, three tocilizumab-treated and three placebo-treated patients completed the double-blind period without relapse before they reached the time at which the GC dose could be reduced to the minimum.

Exploratory subgroup analysis stratified by age category showed consistent results for tocilizumab in time to relapse according to the protocol definition in all subgroups regardless of sex, prednisolone-equivalent GC dose category at randomisation, TAK disease duration or HLA-B52 status and in patients who had previously received disease-modifying antirheumatic drugs (DMARDs)/immunosuppressant treatment (online supplementary figure 1 ).

\section{Safety}

AEs were reported in 14 tocilizumab-treated patients (77.8\%) and 11 placebo-treated patients (61.1\%) (table 4). The most common AEs in both treatment groups were infections and infestations, with 9/18 (50.0\%) tocilizumab-treated patients and 6/18 (33.3\%) placebo-treated patients reporting $\geq 1$ event. Gastrointestinal disorders were reported in 3/18 (16.7\%) tocilizumab-treated patients and 5/18 (27.8\%) placebo-treated patients, and skin and subcutaneous tissue disorders were reported in 6/18 (33.3\%) and 1/18 (5.6\%) patients, respectively. No injection site reactions or systemic injection reactions were reported. One tocilizumab-treated patient and two placebo-treated patients had $\geq 1 \mathrm{SAE}$, including cataract in a tocilizumab-treated patient, cataract in a placebo-treated patient and haemorrhagic shock and gastric ulcer in a placebo-treated patient; no SAEs were considered related to study treatment. No deaths were reported. No anti-tocilizumab antibodies were detected after injection of tocilizumab (see online supplementary appendix for laboratory parameter results).

\section{DISCUSSION}

This study is the first double-blind, randomised controlled trial of anti-cytokine therapy for the treatment of patients with TAK. It was designed to investigate whether tocilizumab treatment enables GC tapering. Investigating the efficacy of therapeutic agents in TAK is challenging because no efficacy endpoint has been validated. Kerr's definition of active disease ${ }^{3}$ has been used in case reports and cohort studies, ${ }^{11} 16212328-30$ but the requirement for imaging studies such as CT, MRI and/or positron emission tomography places a greater burden on patients in terms of exposure and risk from contrast dyes, and it may not be possible to perform imaging for every suspected relapse. Therefore, this study adopted a definition of relapse that was based on the signs and symptoms of TAK without imaging evaluations.

The current study was designed to evaluate time to relapse of TAK with mandatory GC tapering. To induce remission, patients who experienced relapse received GCs at a dose at least twice that of their dose at relapse. Background oral GC dosing was tapered by $10 \%$ per week from week 4 to a minimum of $0.1 \mathrm{mg} /$ $\mathrm{kg} / \mathrm{day}$. All patients did not have to have the same GC doses at baseline because the dose required to induce remission is generally different for each patient. Therefore, stratified randomisation was adopted according to baseline GC dose $(<0.6 \mathrm{mg} / \mathrm{kg} /$ day, $\geq 0.6-<0.8 \mathrm{mg} / \mathrm{kg} /$ day or $\geq 0.8 \mathrm{mg} / \mathrm{kg} /$ day) to ensure even distribution of patients between treatment groups for evaluation of time to relapse of TAK as the primary endpoint.

The primary endpoint was not met in this study; time to relapse was not statistically different between the tocilizumab and placebo groups. However, the results may support the use of tocilizumab for the treatment of patients with refractory TAK. A treatment difference suggesting favour for tocilizumab was observed in the PPS sensitivity analysis. Secondary endpoints, including time to relapse according to Kerr's definition, each of the five categories of symptoms according to the definition of relapse and imaging evaluation, and exploratory subgroup analyses were consistent with the primary endpoint. Results for symptoms other than inflammatory markers suggested that the effect of tocilizumab in time to relapse resulted from the inhibition of IL-6 signalling on the pathogenesis of TAK rather than solely the pharmacodynamic effect of tocilizumab on acute phase reactants. The efficacy and safety of tocilizumab have been reported in patients with giant cell arteritis (GCA), another large vessel vasculitis, in two randomised controlled trials. ${ }^{3132}$ Tocilizumab was effective at maintaining remission and enabling GC tapering in patients with GCA. Considering similarities between the pathogenesis and histopathology of TAK and GCA, ${ }^{22} 33$ these results may lend support to the efficacy of tocilizumab for the treatment of TAK.

It is possible that the sample size of this study was too small because it was based on a previous estimate of tocilizumab efficacy that might have been too high (see online supplementary appendix). The literature review used for the estimation of sample size ${ }^{24}$ reported a relapse rate of $17 \%$ in patients with TAK treated with tocilizumab, and this study presumed a HR of 0.2075 assuming a relapse-free rate of $75 \%$ in the tocilizumab 
group and $25 \%$ in the placebo group at week 24 as a conservative measure; however, studies in the literature review did not include mandatory GC tapering, and patients could have received concomitant immunosuppressants. Consequently, while the $95.41 \% \mathrm{CI}$ covered the presumed value, the resultant HR was numerically higher than the presumption in this study.

Although GCs are effective for the treatment of TAK, adverse effects may preclude long-term treatment. Patients with TAK show increased expression of Th1 and Th17-related cytokines. ${ }^{10}$ However, treatment with GCs decreases Th1 cytokines but spares Th17 cytokines. ${ }^{10}$ Because IL- 6 stimulates the production of Th17 cells and the action of transforming growth factor $\beta$ and IL- $1 \beta,{ }^{34}$ IL-6 inhibition represents a potential therapy for the treatment of TAK with a mode of action different from that of GCs.

In previous reports, intravenous tocilizumab $8 \mathrm{mg} / \mathrm{kg}$ was administered every 4 weeks in patients with active TAK. ${ }^{16}$ 22-26 Although the dosing might have been effective, serum IL-6 levels after tocilizumab administration were higher than those observed in patients with rheumatoid arthritis (RA). ${ }^{1635}$ Higher serum tocilizumab concentrations may be required to completely inhibit IL-6 binding to IL-6R in patients with active TAK. In addition, subcutaneous injection of tocilizumab offers greater convenience to patients than intravenous infusion. Therefore, weekly dosing with tocilizumab subcutaneous $162 \mathrm{mg}$ was selected for this study.

Despite the rather short exposure to tocilizumab in this study, the observed safety was comparable to that for tocilizumab therapy reported in patients with RA. ${ }^{36}{ }^{37}$ In previous reports, the risk for serious infection was related to GC use in patients with RA. ${ }^{37} 38$ Older age is also a risk factor for serious infection in patients with RA treated with tocilizumab. ${ }^{37}$ Although no serious infections were reported in this study and patients with TAK tended to be younger than patients with RA, patients receiving high-dose GCs and tocilizumab should be monitored for serious infection. The SAEs reported in this study are consistent with those observed in patients treated with GCs. ${ }^{3} 39$

There were several limitations in this study. The sample size appears to be restricted for efficacy evaluations, especially regarding ischaemic symptoms and imaging studies and regarding individual symptoms included in the definition of relapse. The efficacy and safety of tocilizumab in combination with DMARDs, immunosuppressants or both in patients with TAK were not investigated. Finally, the study was designed with mandatory GC tapering; further studies are warranted in which GCs can be tapered appropriately, according to the physician's discretion, to determine the long-term steroid-sparing effect of tocilizumab.

In conclusion, although the primary endpoint was not met in this study, the results suggest favour for tocilizumab over placebo and support further investigation of tocilizumab for the treatment of patients with refractory TAK.

Acknowledgements The authors would like to acknowledge all investigators, subinvestigators, study sites and patients who contributed to the TAKT study. They would especially like to thank Seido Ooka, MD, PhD, of St. Marianna University School of Medicine; Hidehiro Yamada, MD, PhD, of St. Marianna University School of Medicine and Seirei Yokohama Hospital; Hiroaki Niiro, MD, PhD, and Hiroshi Tsukamoto, MD, PhD, of Kyushu University; Shogo Banno, MD, PhD, of Aichi Medical University; Naoto Tamura, MD, PhD, and Yoshinari Takasaki, MD, PhD, of Juntendo University; Hajime Yoshifuii, MD, PhD, of Kyoto University; Atsushi Kawakami, MD, PhD, of Nagasaki University; Shunsuke Furuta, MD, PhD, of Chiba University; Tatsuya Atsumi, MD, PhD, of Hokkaido University; Katsuya Suzuki, MD, PhD, of Keio University; and Ryoki Hara, MD, PhD, of Yokohama City University. Professional writing and editorial assistance was provided by Jennifer Adlington, $\mathrm{PhD}$, and Sara Duggan, PhD, on behalf of F. Hoffmann-La Roche.

Contributors YN was involved in conception and design, acquisition of data, analysis and interpretation of data, drafting the article and revising it critically for important intellectual content. NN was involved in conception and design, analysis and interpretation of data, drafting the article and revising it critically for important intellectual content. MI, YT, ST and TI were involved in conception and design, acquisition of data, interpretation of data and revising the article critically for important intellectual content. SY was involved in conception and design, interpretation of data and revising the article critically for important intellectual content. SY and AN were involved in conception and design, analysis and interpretation of data and drafting the article. YN, AN and SY had full access to all the data in the study and take responsibility for its integrity and the data analysis.

Funding This study was funded by Chugai Pharmaceutical Co. Funding for manuscript preparation was provided by F. Hoffmann-La Roche.

Competing interests YN reports personal fees from Chugai as a consultant of the sponsor-initiated clinical trial (Chugai Pharmaceutical Co.) using tocilizumab for Takayasu arteritis; grants and personal fees from Chugai; grants and personal fees from Astellas, Pfizer, and MSD outside the submitted work; grants from Takeda, Otsuka, Bayer outside the submitted work; and personal fees from Daiichi Sankyo and Kowa Pharmaceutical Co. outside the submitted work. Ml reports personal fees from Chugai during the conduct of the study; personal fees from Chugai; and grants and personal fees from Ono, Mitsubishi Tanabe, Daiichi Sankyo, Otsuka and Teijin Pharma outside the submitted work. ST reports grants and personal fees from Chugai during the conduct of the study; grants and personal fees from Eisai, Takeda, Bristol-Myers Squibb and Tanabe-Mitsubishi; and personal fees from Pfizer, Ayumi, Asahi Kasei Pharma, AbbVie, Santen, Nihon Pharmaceutical, Japan Blood Products Organization, Teijin and UCB Japan outside the submitted work. YT reports grants and personal fees from Chugai during the conduct of the study; grants and personal fees from Daiichi Sankyo, Astellas, Pfizer, Mitsubishi-Tanabe and Bristol-Myers Squibb outside the submitted work; grants from MSD, Takeda, AbbVie, Kyowa-Kirin, Eisai and Ono outside the submitted work; and personal fees from YL Biologics, Eli Lilly, Sanofi, Janssen and UCB outside the submitted work. TI reports personal fees from Chugai during the conduct of the study and personal fees from Chugai, Ono, Pfizer, Mitsubishi-Tanabe and Astellas outside the submitted work. SY reports personal fees from Chugai during the conduct of the study and personal fees from Chugai outside the submitted work. AN reports personal fees from Chugai during the conduct of the study. SY reports personal fees from Chugai during the conduct of the study. NN reports personal fees from Chugai during the conduct of the study and grants and personal fees from Chugai outside the submitted work and has a patent for tocilizumab with royalties paid by Chugai. S Ooka reports personal fees from Chugai during the conduct of the study and a grant from Chugai outside the submitted work. $\mathrm{H}$ Yamada reports personal fees from Chugai during the conduct of the study and personal fees from Chugai, Teijin, Asahi Kasei, Astellas, Ono, Bristol-Myers Squibb, Pfizer, Eisai, Mitsubishi Tanabe, Janssen, AbbVie, Actelion, Nippon Shinyaku, GlaxoSmithKline and Bayer outside the submitted work. H Niiro reports personal fees from Chugai during the conduct of the study; grants and personal fees from Chugai, Mitsubishi Tanabe, Astellas, Bristol-Myers Squibb and Takeda outside the submitted work; and personal fees from Pfizer and Eisai outside the submitted work. H. Tsukamoto reports personal fees from Chugai during the conduct of the study and personal fees from Chugai, Astellas, Takeda, Pfizer, AbbVie, Eisai, Mitsubishi-Tanabe, Bristol-Myers Squibb, Ayumi, Mylan, Asahi Kasei Pharma, Actelion, Daiichi Sankyo, Nippon Kayaku, Thermo Fisher Diagnostics, Kissei and Eli Lilly outside the submitted work. S Banno reports personal fees from Chugai during the conduct of the study; personal fees from Kissei outside the submitted work; and grants from Chugai, Teijin, Kissei, Mitsubishi Tanabe, Takeda, Pfizer, Eisai, AbbVie, Bristol-Myers Squibb, Ono, Astellas, Janssen and UCB outside the submitted work. N Tamura reports personal fees from Chugai during the conduct of the study: grants and personal fees from Janssen, Astellas, Eisai, AbbVie, Pfizer and Daiichi Sankyo outside the submitted work; and personal fees from UCB, Bristol-Myers Squibb and Novartis outside the submitted work. Y Takasaki reports personal fees from Chugai during the conduct of the study and grants and personal fees from Santen, Daiichi Sankyo, Mitsubishi Tanabe, Bristol-Myers Squibb, AstraZeneca, Astellas, MSD, Chugai, Asahi Kasei, Eisai and Janssen outside the submitted work. $\mathrm{H}$ Yoshifuji reports personal fees from Chugai during the conduct of the study. A Kawakami reports personal fees from Chugai during the conduct of the study; grants and personal fees from Ono, Mitsubishi Tanabe, Takeda, Astellas, AbbVie, MSD, AstraZeneca, Actelion, Eisai, Kissei, Santen, Daiichi Sankyo, Pfizer, Sanofi, Asahi Kasei, Taisho Toyama, Teijin, Sumitomo Dainippon, Eli Lilly, Bristol-Myers Squibb and Janssen outside the submitted work; grants from Mochida, Boehringe Ingelheim, Otsuka and Kowa outside the submitted work; and personal fees from Novartis outside the submitted work. S Furuta reports personal fees from Chugai during the conduct of the study. TAtsumi reports personal fees from Chugai, Eli Lilly, GlaxoSmithKline, Pfizer and UCB Japan during the conduct of the study; grants and personal fees from Astellas, Takeda, Mitsubishi Tanabe, Chugai, Pfizer, Daiichi Sankyo, Eisai and AbbVie outside the submitted work; grants from Otsuka outside the submitted work; personal fees from Bristol-Myers Squibb outside the submitted work. K Suzuki reports personal fees from Chugai during the conduct of the study; grants and personal fees from Eisai, Bristol-Myers Squibb and Kissei outside the submitted work; grants from Daiichi Sankyo outside the submitted work; personal fees from AbbVie, Astellas, Chugai, Fuji Film, Janssen, Mitsubishi Tanabe, Pfizer, Shionogi, Takeda and UCB Japan outside the submitted work. R Hara reports 
personal fees from Chugai during the conduct of the study and personal fees from Chugai, Eisai and Toshiba Medical outside the submitted work.

\section{Patient consent Obtained.}

Ethics approval The study was conducted in accordance with the Declaration of Helsinki and Good Clinical Practice and was approved by the Institutional Review Board.

Provenance and peer review Not commissioned; externally peer reviewed.

Open Access This is an Open Access article distributed in accordance with the Creative Commons Attribution Non Commercial (CC BY-NC 4.0) license, which permits others to distribute, remix, adapt, build upon this work non-commercially, and license their derivative works on different terms, provided the original work is properly cited and the use is non-commercial. See: http://creativecommons.org/ licenses/by-nc/4.0/

(c) Article author(s) (or their employer(s) unless otherwise stated in the text of the article) 2018. All rights reserved. No commercial use is permitted unless otherwise expressly granted.

\section{REFERENCES}

1. JCS Joint Working Group. Guideline for management of vasculitis syndrome (JCS 2008). Japanese Circulation Society. Circ J 2011;75:474-503.

2. Hall S, Barr W, Lie JT, et al. Takayasu arteritis. A study of 32 North American patients. Medicine 1985;64:89-99.

3. Kerr GS, Hallahan CW, Giordano J, et al. Takayasu arteritis. Ann Intern Med 1994:120:919-29.

4. Watanabe Y, Miyata T, Tanemoto K. Current clinical features of new patients with takayasu arteritis observed from cross-country research in Japan: age and sex specificity. Circulation 2015;132:1701-9.

5. Johnston SL, Lock RJ, Gompels MM. Takayasu arteritis: a review. J Clin Pathol 2002;55:481-6.

6. Brunner J, Feldman BM, Tyrrell PN, et al. Takayasu arteritis in children and adolescents. Rheumatology 2010;49:1806-14.

7. Noris $\mathrm{M}$, Daina E, Gamba S, et al. Interleukin- 6 and rantes in takayasu arteritis: a guide for therapeutic decisions? Circulation 1999;100:55-60.

8. Park MC, Lee SW, Park YB, et al. Serum cytokine profiles and their correlations with disease activity in takayasu's arteritis. Rheumatology 2006;45:545-8.

9. Alibaz-Oner F, Yentür SP, Saruhan-Direskeneli G, et al. Serum cytokine profiles in Takayasu's arteritis: search for biomarkers. Clin Exp Rheumatol 2015;33:S-32-5.

10. Saadoun D, Garrido M, Comarmond C, et al. Th1 and Th17 cytokines drive inflammation in takayasu arteritis. Arthritis Rheumatol 2015;67:1353-60.

11. Kong X, Sun Y, Ma L, et al. The critical role of IL-6 in the pathogenesis of takayasu arteritis. Clin Exp Rheumatol 2016;34(Suppl 97):S21-7.

12. Koster MJ, Matteson EL, Warrington KJ. Recent advances in the clinical management of giant cell arteritis and takayasu arteritis. Curr Opin Rheumatol 2016;28:211-7.

13. Hoffman GS, Leavitt RY, Kerr GS, et al. Treatment of glucocorticoid-resistant or relapsing Takayasu arteritis with methotrexate. Arthritis Rheum 1994;37:578-82.

14. Valsakumar AK, Valappil UC, Jorapur V, et al. Role of immunosuppressive therapy on clinical, immunological, and angiographic outcome in active takayasu's arteritis. J Rheumatol 2003:30:1793-8.

15. Shinjo SK, Pereira RM, Tizziani VA, et al. Mycophenolate mofetil reduces disease activity and steroid dosage in takayasu arteritis. Clin Rheumatol 2007;26:1871-5.

16. Nakaoka Y, Higuchi K, Arita Y, et al. Tocilizumab for the treatment of patients with refractory takayasu arteritis. Int Heart J 2013;54:405-11.

17. Mekinian A, Néel A, Sibilia J, et al. Efficacy and tolerance of infliximab in refractory takayasu arteritis: French multicentre study. Rheumatology 2012;51:882-6.

18. Clifford A, Hoffman GS. Recent advances in the medical management of takayasu arteritis: an update on use of biologic therapies. Curr Opin Rheumatol 2014;26:7-15.
19. Mekinian A, Comarmond C, Resche-Rigon M, et al. Efficacy of biological-targeted treatments in takayasu arteritis: multicenter, retrospective study of 49 patients. Circulation 2015;132:1693-700.

20. Schmidt J, Kermani TA, Bacani AK, et al. Tumor necrosis factor inhibitors in patients with Takayasu arteritis: experience from a referral center with long-term followup. Arthritis Care Res 2012;64:1079-83.

21. Nishimoto N, Nakahara H, Yoshio-Hoshino N, et al. Successful treatment of a patient with Takayasu arteritis using a humanized anti-interleukin-6 receptor antibody. Arthritis Rheum 2008;58:1197-200.

22. Unizony S, Arias-Urdaneta L, Miloslavsky E, et al. Tocilizumab for the treatment of large-vessel vasculitis (giant cell arteritis, Takayasu arteritis) and polymyalgia rheumatica. Arthritis Care Res 2012;64:1720-9.

23. Tombetti E, Franchini S, Papa M, et al. Treatment of refractory takayasu arteritis with tocilizumab: 7 Italian patients from a single referral center.J Rheumatol 2013;40:2047-51

24. Abisror N, Mekinian A, Lavigne C, et al. Tocilizumab in refractory Takayasu arteritis: a case series and updated literature review. Autoimmun Rev 2013;12:1143-9.

25. Goel R, Danda D, Kumar $S$, et al. Rapid control of disease activity by tocilizumab in 10 'difficult-to-treat' cases of takayasu arteritis. Int J Rheum Dis 2013;16:754-61.

26. Salvarani C, Magnani L, Catanoso MG, et al. Rescue treatment with tocilizumab for takayasu arteritis resistant to TNF- $\alpha$ blockers. Clin Exp Rheumatol 2012;30(Suppl 70):S90-3.

27. Stubenrauch $\mathrm{K}$, Wessels $\mathrm{U}$, Birnboeck $\mathrm{H}$, et al. Subset analysis of patients experiencing clinical events of a potentially immunogenic nature in the pivotal clinical trials of tocilizumab for rheumatoid arthritis: evaluation of an antidrug antibody ELISA using clinical adverse event-driven immunogenicity testing. Clin Ther 2010;32:1597-609.

28. Andrews J, Al-Nahhas A, Pennell DJ, et al. Non-invasive imaging in the diagnosis and management of takayasu's arteritis. Ann Rheum Dis 2004:63:995-1000.

29. Kato $Y$, Terashima M, Ohigashi $H$, et al. Vessel wall inflammation of takayasu arteritis detected by contrast-enhanced magnetic resonance imaging: association with disease distribution and activity. PLOS One 2015;10:e0145855.

30. Misra DP, Chaurasia S, Misra R. Increased circulating Th17 Cells, serum IL-17A, and IL-23 in takayasu arteritis. Autoimmune Dis 2016;2016:1-8.

31. Villiger PM, Adler $S$, Kuchen $S$, et al. Tocilizumab for induction and maintenance of remission in giant cell arteritis: a phase 2, randomised, double-blind, placebocontrolled trial. Lancet 2016;387:1921-7.

32. Stone JH, Tuckwell K, Dimonaco $\mathrm{S}$, et al. Trial of tocilizumab in giant-cell arteritis. N Eng/ J Med 2017;377:317-28.

33. Maksimowicz-McKinnon K, Clark TM, Hoffman GS. Takayasu arteritis and giant cell arteritis: a spectrum within the same disease? Medicine 2009;88:221-6.

34. Manel N, Unutmaz D, Littman DR. The differentiation of human $\mathrm{T}(\mathrm{H})-17$ cells requires transforming growth factor-beta and induction of the nuclear receptor RORgammat. Nat Immunol 2008;9:641-9.

35. Nishimoto N, Terao K, Mima T, et al. Mechanisms and pathologic significances in increase in serum interleukin-6 (il-6) and soluble il-6 receptor after administration of an anti-il-6 receptor antibody, tocilizumab, in patients with rheumatoid arthritis and castleman disease. Blood 2008;112:3959-64.

36. Nishimoto N, Ito K, Takagi N. Safety and efficacy profiles of tocilizumab monotherapy in Japanese patients with rheumatoid arthritis: meta-analysis of six initial trials and five long-term extensions. Mod Rheumatol 2010;20:222-32.

37. Koike T, Harigai M, Inokuma $\mathrm{S}$, et al. Effectiveness and safety of tocilizumab: postmarketing surveillance of 7901 patients with rheumatoid arthritis in Japan. J Rheumatol 2014;41:15-23.

38. Listing J, Gerhold K, Zink A. The risk of infections associated with rheumatoid arthritis, with its comorbidity and treatment. Rheumatology 2013;52:53-61.

39. Proven A, Gabriel SE, Orces C, et al. Glucocorticoid therapy in giant cell arteritis: duration and adverse outcomes. Arthritis Rheum 2003;49:703-8. 